\title{
Neural, cognitive, and neuroimaging markers of the suicidal brain
}

\author{
This article was published in the following Dove Press journal: \\ Reports in Medical Imaging \\ 25 May 2015 \\ Number of times this article has been viewed
}

\section{Thomas Sobanski' \\ Karl-Jürgen Bär ${ }^{2}$ \\ Gerd Wagner ${ }^{2}$}

'Department of Psychiatry, Psychotherapy and Psychosomatic Medicine, Thüringen-Kliniken "Georgius Agricola" GmbH, Saalfeld, Germany; ${ }^{2}$ Department of Psychiatry and Psychotherapy, Psychiatric Brain and Body Research Group Jena, Jena University Hospital, Jena, Germany

Correspondence: Gerd Wagner Department of Psychiatry and Psychotherapy, Psychiatric Brain and Body Research Group Jena, Jena University Hospital, Philosophenweg 3, Jena 07743 , Germany

Tel +49 364I 939042 I

Fax +4936419390102

Email wagner.gerd@uni-jena.de
Abstract: Suicidal behavior (SB) is characterized by the occurrence of suicide attempts with substantial intent to die. SB is a major health problem worldwide. In the great majority of cases, SB occurs in patients suffering from psychiatric disorders, mainly from affective disorders or schizophrenia. Despite this high association, there is growing evidence from genetic studies that SB might represent a psychiatric condition on its own. This review provides an overview of the most significant neurobiological and neurocognitive findings in SB. We provide evidence for specific dysfunctions within the serotonergic system, for distinct morphological abnormalities in the gray and white matter composition as well as for neurofunctional alterations in the fronto-striatal network. Additionally, the putative role of impulsivity and hopelessness as trait-like risk factors for SB is outlined. Both the personality traits are associated with altered prefrontal cortex function and deficits in cognitive and affective control similar to the findings in SB. Given the difficulties of clinical risk assessment, there is a need to identify specific markers that can predict SB more reliably. Some recent neurocognitive and functional/structural neuroimaging findings might be appropriate to use as SB indicators in the close future.

Keywords: suicidal behavior, biological markers, serotonin, hopelessness, impulsivity, major depressive disorder, fMRI, PET, SPECT

\section{Introduction}

Suicide is one of the most frequent causes of unnatural death. According to the United Nations, ${ }^{1}$ more people die by suicide every year than by both homicide and war. About one million suicides and ten million suicide attempts occur worldwide each year, representing a mortality rate of 14.5 deaths per 100,000 habitants per year. ${ }^{2}$ More than $90 \%$ of all suicide completers suffer from mental illness, most commonly from mood disorders. ${ }^{3,4}$ Major depressive disorder (MDD) is a common and highly debilitating condition, which affects approximately one in ten people in Europe. ${ }^{5}$ The risk of suicide is 17 times higher in people with mood disorders than in the general population. ${ }^{6}$ Follow-up studies documented that $10 \%-15 \%$ of patients with MDD die by suicide during the course of the disease. ${ }^{7}$ However, despite this remarkable high association, it remains unclear why most people with mood disorders never attempt suicide. This indicates that a predisposition to suicidal behavior (SB) may exist, which might be to some extent independent of the psychiatric disorder itself. ${ }^{4,8} \mathrm{SB}$ in this sense refers to the occurrence of suicide attempts with at least some intent to die. The clinical evaluation of individual suicide risk is difficult because people planning a suicidal act are often unwilling or unable to report their intentions. Accordingly, the assessment of clinical risk factors yields only weak predictive power. ${ }^{9}$ Given these facts, there is a 
strong need for additional tests predicting SB more reliably. Nock et $\mathrm{al}^{10}$ reported that implicit cognition of death and suicide as measured by a computer-administered neurocognitive paradigm exceeded the predictive validity of known risk factors (eg, depression, suicide-attempt history) and clinicians' predictions. In the near future, even more precise estimates may become possible by the use of structural and functional neuroimaging approaches providing markers of an increased suicide risk. ${ }^{11,12}$

During the last two decades, a variety of studies have been published on neurobiological and neurofunctional alterations in SB. The aim of this review is to provide a comprehensive overview on most significant findings. An exhaustive presentation of the research is barely possible and certainly beyond the scope of this work.

\section{Theoretical concept of SB}

$\mathrm{SB}$ is a complex and multifaceted phenomenon with several state- and trait-dependent factors. A stress-diathesis model has been introduced by $\mathrm{Mann}^{4}$ to describe the potential interaction between risk factors for suicidal ideation (SI) and SB. In this paper, we focused on SB, which is a more circumscribed construct when compared to SI. Therefore, we propose a "diathesis-stress model" as shown in Figure 1. According to this model, hopelessness and impulsivity are considered as trait-like components of the diathesis for SB, while acute psychiatric disorders such as MDD or psychosocial crises are considered as state-dependent stressors. The concepts of impulsivity and hopelessness and their neurobiological correlates will be discussed in more detail in the subsequent sections.

With regard to potential animal models of SB, no convincing animal models have been constructed to date. Preti ${ }^{13}$ stated in his review that despite the investigation of thousands of animals, suicide in nonhuman species has not been observed in nature. Therefore, the current animal research

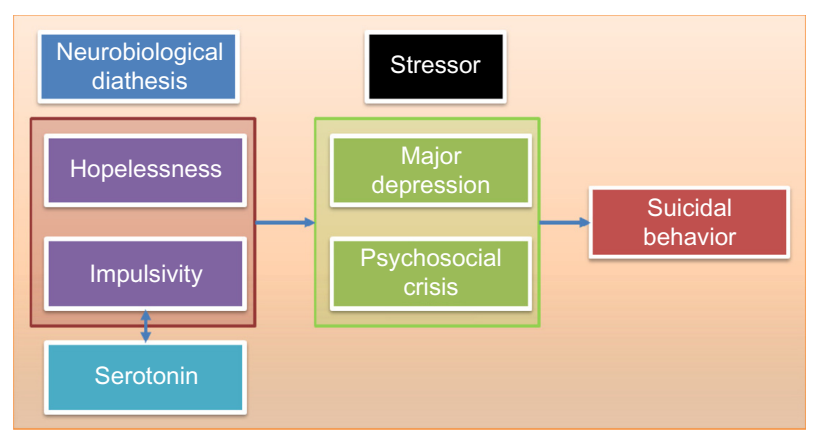

Figure I The diathesis-stress model of suicidal behavior. is focusing on similar endophenotypes of $\mathrm{SB}$ as proposed in the current human research, ie, hopelessness ("learned helplessness" in the animal research) and impulsivity/ aggression. ${ }^{13}$ The presentation of the animal research findings is, however, beyond the scope of this work.

\section{Genetic factors in SB}

Twin studies have revealed higher concordance rate for suicide in monozygotic than dizygotic twins $(24.1 \%$ vs $2.8 \%) .{ }^{14}$ In adoption studies, suicide rates are fourfold to sixfold higher in the biological relatives of adoptees who die by suicide compared with adoptive relatives. ${ }^{15}$ Family studies in patients with MDD have shown that predisposition to $\mathrm{SB}$ is transmitted independent of the psychiatric disorder. ${ }^{8}$ The heritability of SB is high, about $30 \%-50 \%$ for a broad definition of suicidality that includes ideation and plans ${ }^{16}$ and approximately $55 \%$ for serious suicide attempts. ${ }^{17}$ Given this evidence, it has been proposed that SB in patients with MDD might represent a separate nosological (sub-)entity which might be independent of MDD itself. ${ }^{16,18}$

However, considering the fact that SB is a highly complex human behavior, genetic effects are believed to act through intermediate phenotypes, which are conceptualized as mediators between genes and SB. ${ }^{19}$ There are considerable data suggesting that impulsive-aggressive personality traits may act as such an intermediate phenotype of SB. ${ }^{8}$ Dumais et $\mathrm{al}^{20}$ and McGirr et $\mathrm{al}^{21}$ reported that higher levels of impulsive behavior were related to increased suicide risk among patients with the same psychiatric diagnosis, such as major depression. Furthermore, Kim et al $^{22}$ observed that familial aggregation of SB co-segregates with familial transmission of impulsive-aggressive behavior.

Neurobiological evidence implicates serotonergic dysfunction in SB as well as in impulse control disorder. For instance, Lidberg et $\mathrm{al}^{23}$ observed low cerebrospinal fluid (CSF) levels of a serotonin metabolite (5-hydroxyindoleacetic acid) in suicide attempters as well as in mentally ill violent offenders. Research has therefore focused on the association between SB and various serotonergic genes (tryptophan hydroxylase [TPH] genes TPH1 and TPH2; serotonin transporter gene with functional promoter polymorphism 5-HTTLPR; serotonin receptor genes HTR1A, HTR2A, HTR1B, HTR2C, and monoamine oxidase A [MAOA] gene). Several studies report associations between $\mathrm{SB}$ and variation on the TPH1 gene ${ }^{24}$ and between SB and 5-HTTLPR promoter polymorphism in the serotonin transporter gene. ${ }^{25,26}$ With regards to the $\mathrm{TPH} 2$ gene and serotonin receptor genes, results are inconsistent. Studies on endophenotypes 
of suicidality, such as aggression and impulsive behavior, showed positive associations for the TPH1, HTR2A, and MAOA genes, ${ }^{27}$ but further replication of these findings is necessary.

\section{Neurochemical abnormalities associated with SB}

The majority of studies on the neurobiology of SB reported neurochemical alterations of the serotonergic system. As already stated in the previous paragraph low serotonin turnover in the central nervous system in SB is among the most robust findings. ${ }^{28}$ In contrast, there are no consistent changes regarding dopamine or norepinephrine metabolites. ${ }^{29}$ Serotonin is synthesized exclusively in nuclei in the brainstem, the dorsal and median raphe nuclei (DRN and MRN). Abnormal function of DRN and MRN in SB is a wellestablished fact. ${ }^{4}$ Stockmeier et $\mathrm{al}^{30}$ reported an increase in the binding of a selective 5-hydroxytryptamine ${ }_{1 \mathrm{~A}}\left(5-\mathrm{HT}_{1 \mathrm{~A}}\right)$ agonist 3H-8-hydroxy-2-( $N$-dipropylamino)tetralin $([3 \mathrm{H}] 8$ $\mathrm{OH}-\mathrm{DPAT}$ ) to serotonin-1A receptors in the DRN in suicide victims with MDD, indicating diminished serotonergic activity. Similarly, postmortem neuronal TPH2 expression in the DRN has been observed to be increased in suicide victims with MDD, ${ }^{31,32}$ which has been interpreted as a compensatory mechanism to a reduction in serotonergic transmission in both cortical and subcortical regions of depressed patients who committed suicide. Indeed, decreased serotonin transporter (5-Hydroxytryptamintransporter [5-HTT]) binding in the midbrain, ${ }^{33,34}$ pons, basal ganglia, ${ }^{35}$ and cerebellum ${ }^{36}$ was also reported in in vivo studies of suicide attempters.

The DRN and MRN give rise to ascending projections to the thalamus and other subcortical and cortical brain regions. In recent research of the serotonergic system in $\mathrm{SB}$, the prefrontal cortex (PFC) has attracted considerable attention. Due to its putatively significant role in $\mathrm{SB}$, studies with various methodological approaches have focused on the PFC and have shown alterations in this region. Postmortem studies in suicide victims reported increased postsynaptic 5-HT1A and 5-HT2A receptor binding in $\mathrm{PFC},{ }^{37}$ and in particular a reduction in serotonin transporter binding in ventromedial PFC (VMPFC) ${ }^{38}$ and ventrolateral PFC (VLPFC), ${ }^{39}$ indicating a potential compensatory mechanism of low serotonergic neuron activity. Audenaert et $\mathrm{al}^{40}$ investigated suicide attempters in vivo and found reduced 5-HT2A receptor binding in the bilateral frontal cortex, mainly in the dorsolateral PFC (DLPFC). In addition, the authors described a negative correlation between binding intensity and both hopelessness and harm avoidance. Leyton et $\mathrm{al}^{41}$ reported reduced alpha-[11C]methyl-L-tryptophan trapping indicating decreased serotonin synthesis in the orbitofrontal cortex (OFC) and VMPFC in high-lethality suicide attempters. Moreover, there was a negative correlation between suicidal intent and alpha-[11C]methyl-L-tryptophan trapping in these regions. The authors concluded that low serotonin synthesis in the medial PFC may lower the threshold for SB.

Oquendo et $\mathrm{al}^{42}$ investigated depressed high-lethality and low-lethality suicide attempters by positron emission tomography (PET) and found decreased metabolic activity in the anterior cingulate gyrus (anterior cingulate cortex [ACC]) and VMPFC in depressed high-lethality suicide attempters. This group difference increased when serotonergic challenge with fenfluramine was carried out. Lower VMPFC activity was associated with the degree of impulsivity and suicidal intent, but not with depression.

The PFC is largely innervated by serotonergic fibers. ${ }^{43}$ Serotonergic projections from the DRN to the VMPFC, OFC, and DLPFC are of utmost importance because these frontal brain areas are involved in the executive functions of inhibition and decision making, affective control, and reward processing. Reduced serotonergic input into the VMPFC, OFC, and DLPFC may result in impaired affect regulation as well as in diminished behavioral control and thereby in a greater propensity to act on powerful emotions such as suicidal or aggressive feelings. Thus, both developmental and genetic factors may be responsible for the lower central nervous system serotonergic activity in SB..$^{28,44}$

\section{Alterations in brain structure of patients with SB Postmortem studies}

Postmortem studies often demonstrated that subjects, who died from suicide, have alterations in the density and size of neuronal and glial cells in the fronto-cingulate brain regions as well as in the serotonin-producing raphe nuclei in the brainstem. Rajkowska et $\mathrm{al}^{45}$ reported reduced cortical thickness of the OFC in depressed patients due to decreases not only in glial cells but also in neuronal cell density. Additionally, the authors reported a similar reduction in cell density for the DLPFC. Ongur et $\mathrm{al}^{46}$ reported a considerable reduction of glial cells in the subgenual cingulate cortex in patients with MDD. The major part of the investigated patients in these two studies committed suicide. Mechawar ${ }^{47}$ who compared depressed suicide completers to matched natural death controls found hypertrophic white matter fibrous astrocytes in the ACC. In a prior study of this group, altered dendritic branching of the ACC pyramidal neurons was reported in 
depressed suicides. ${ }^{48}$ Beside alterations in cortical regions, Underwood et $\mathrm{al}^{49}$ demonstrated a higher number and density of neurons in the DRN. Furthermore, Arango et $\mathrm{al}^{39}$ reported in suicide completers an increased serotonin 5-HT1A receptor (postsynaptic in cortex) binding and decreased serotonin transporter (presynaptic) binding in the VLPFC.

Thus, postmortem studies provided strong evidence for specific morphological alteration in the gray and white matter composition, which might be a consequence of an abnormal serotonergic transmission from DRN to the frontal and anterior cingulate brain regions.

\section{Abnormalities in gray matter}

Relatively few in vivo studies have investigated differences in brain structure between patients with and without SB. Ahearn et $\mathrm{al}^{50}$ reported in a qualitative study based on experts' ratings that depressed patients with SB demonstrated significantly more subcortical gray matter hyperintensities compared with patients without such a history. Monkul et $\mathrm{al}^{51}$ investigated neuroanatomical differences by means of manual tracing of a priori defined regions-of-interest and detected decreased OFC volumes and increased amygdala volumes in seven depressed patients with a history of suicide attempt. Using voxel-based morphometry (VBM), Aguilar et al ${ }^{52}$ reported decreased gray matter volumes in the orbitofrontal and superior temporal cortex in patients with schizophrenia and SB. Giakoumatos et $\mathrm{al}^{53}$ detected in schizophrenic patients with SB reduced gray matter volume in several cortical regions in the frontal, temporal, and parietal lobes as well as in the thalamus by means of VBM.

Vang et $\mathrm{al}^{54}$ reported lower volume of caudate nucleus and globus pallidus in suicide attempters, which negatively correlated with serotonin transporter binding potential. Wagner et $\mathrm{al}^{55}$ have shown by means of VBM that depressed patients with a high risk of suicide (own SB or first-degree relatives with SB) had significantly decreased gray matter density in the ACC and in the caudate nucleus. Dombrovski et $\mathrm{al}^{56}$ detected lower putamen volumes in older depressed patients with SB.

To ensure better comparability with postmortem studies, Wagner et $\mathrm{al}^{11}$ used an automated surface-based approach (FreeSurfer) and analyzed differences in the cortical thickness on a node-by-node basis covering the entire cortex. The main finding was that patients with high risk for suicide showed significantly thinner cortex in the left DLPFC and VLPFC as well as in the ACC in contrast to non-high-risk patients. This finding corresponds well with the reduction in neuronal and glial cell size and density in the frontal and anterior cingulate cortices as observed in postmortem studies.

\section{Abnormalities in white matter}

With respect to the white matter abnormalities in subjects with SB, Ehrlich et al consistently detected in several studies ${ }^{57-61}$ white matter hyperintensities on T2-weighted magnetic resonance imaging (MRI) images using a modified Coffey rating scale in children, adolescents, and young adults. Recent studies using more sophisticated methods such as diffusion tensor imaging (DTI) detected decreased fractional anisotropy as one parameter of white matter integrity in the left anterior limb of the internal capsule and the right lentiform nucleus in depressed patients with SB. ${ }^{62}$ In a recent study, Jia et al ${ }^{63}$ observed in line with their previous study a disrupted frontothalamic connectivity in depressed patients with SB in terms of reduced fiber projections through the anterior limb of the internal capsule connecting the left OFC and thalamus. DTI studies of Mahon et $\mathrm{al}^{64}$ and Olvet et $\mathrm{al}^{65}$ lend further support to the notion of the abnormal frontal connectivity reporting reduced orbitofrontal fractional anisotropy in the bipolar patients with SB and reduced medial frontal fractional anisotropy in patients with MDD and SB.

A further study revealed a reduced volume of the posterior part of the corpus callosum in elderly patients with MDD (mean age of 72 years) and a history of suicide attempt.

Taken together, findings of abnormal white matter connectivity, predominantly in the fronto-thalamic pathway, corroborate previous structural and postmortem results of reduced prefrontal, anterior cingulate and striatal volume, as well as reduced cortical thickness. Striatal fibers from the ACC project ventrally into the head of caudate in close proximity to the internal capsule. ${ }^{66}$ Moreover, the PFC has extensive projections to the striatum via the anterior internal capsule. Thus, these findings provide strong evidence for a potential dysconnectivity in the fronto-striato-thalamic network in patients with $\mathrm{SB}$ and might represent a specific neurobiological marker.

\section{Neuroimaging of impulsivity}

Genetic effects are believed to act through intermediate phenotypes, ${ }^{19}$ which are conceptualized as a mediator between genes and SB. There are considerable data suggesting that impulsive-aggressive personality traits may act as such an intermediate phenotype of SB. ${ }^{8}$ Impulsivity can be defined as a function of inhibitory control, and it is understood to be a trait-like phenomenon. ${ }^{67}$ Impulsive behavior can be assessed using the Barratt Impulsivity Scale. ${ }^{68}$ However, neuropsychological testing based on response inhibition or cognitive inhibition may better quantify this construct. Previous studies using Stroop and stop-signal tasks reported 
a significant relationship between decreased response inhibition and abnormal impulsivity in attention deficit hyperactivity disorder, ${ }^{69}$ antisocial personality disorder, ${ }^{70}$ and trichotillomania. ${ }^{71}$ The serotonergic system is assumed to be strongly involved in impulsivity. ${ }^{72}$ For example, serotonin depletion has been found to increase impulsive aggression in men $^{73}$ and in women. ${ }^{74}$

Functional MRI (fMRI) studies with cognitive inhibition tasks consistently reported activation in a fronto-cingulo-striatal network in healthy subjects. Whereas VLPFC, DLPFC, and striatum as parts of the fronto-basal-ganglia inhibition network are predominately involved in the inhibition of irrelevant motor responses, ${ }^{75}$ the function of the ACC has been mainly seen in monitoring potential conflicts and performance adjustment. ${ }^{76}$ In light of this, it is an interesting fact that several studies have revealed altered ACC and PFC function in both suicidal and impulsive behavior. Dombrovski et $\mathrm{al}^{77}$ investigated SB with late-life depression using a reward task. The authors reported decreased pregenual ACC response to high expected reward that was associated with increased impulsivity. Pan et al ${ }^{78}$ investigated SB in depressed adolescents by a go-no-go response inhibition and motor control task. The fMRI response revealed reduced ACC activation in the SB group compared with depressive controls. Frankle et $\mathrm{al}^{79}$ reported reduced 5-HTT availability in the ACC in patients with impulsive aggression compared with healthy subjects in a PET study. Another group investigated patients with borderline personality disorder and impulsive behavior by rCMRglu PET and found bilaterally decreased regional cerebral glucose metabolism in the VMPFC and OFC. ${ }^{80}$

Taken together, there is considerable evidence from neuropsychological and neurofunctional studies that both suicidal and impulsive behavior may be accompanied by deficits in cognitive inhibition and behavioral inhibition. These deficits presumably are based on blunted activation of the fronto-striatal network, which is strongly involved in reward processing and behavioral/affective control. The abnormalities observed in this network may constitute the neurobiological basis for an increased predisposition to SB.

\section{Neuroimaging of hopelessness}

According to the diathesis-stress model proposed in the present review (Figure 1) hopelessness, besides impulsivity, is a further clinical feature assumed to increase the risk of SB. It is a stable personality trait, which can be measured by the Beck hopelessness scale, a 20 -item self-rating inventory. ${ }^{81}$ Hopelessness is defined as a system of cognitive schemas encompassing negative expectations about the future, about accomplishing goals, and about the likelihood of achieving success. ${ }^{81}$ Hopelessness can be conceptualized as part of negative self-referential processing (ie, thinking). It has been shown to be better correlated with SB than scores at depression rating scales in prospective cohort studies. ${ }^{82,83}$ In a study by van Heeringen et $\mathrm{al},{ }^{84}$ the levels of hopelessness were significantly negatively correlated with the 5-HT2A binding index, indicating its association with decreased serotonergic transmission in SB, as is similar for impulsivity.

The majority of neuroimaging studies investigating selfreferential processes found evidence for the strong involvement of cortical midline structures, ie, the posterior cingulate cortex, VMPFC, and dorsomedial PFC during processing of self-related information. ${ }^{85,86}$ van der Meer et al ${ }^{86}$ included 20 PET or fMRI studies on self-referential processing in a meta-analysis and found that the VMPFC was a key structure involved in the processing of self-related in contrast to other-related stimuli. In a study of our group, we investigated the neural correlates of self-referential processing in healthy individuals. ${ }^{87}$ The main result was that the VMPFC was specifically engaged during negative affective self-referential processing and its activity was significantly related to the degree of depression-like symptoms in participants. Lemogne et $\mathrm{al}^{88}$ underlined in a recent review the importance of the VMPFC in negative self-referential processing (concept closely related to hopelessness) in MDD and emphasized its putative negative impact on cognitive functions due to aberrant functional connectivity between ACC and VMPFC. Furthermore, recent fMRI studies of Grimm et $\mathrm{al}^{89}$ and Cooney et $\mathrm{al}^{90}$ have consistently reported enhanced activation in the VMPFC due to negative self-referential processing.

In summary, these results provide robust evidence for the VMPFC to be a critical brain region for hopelessness and negative self-related processing as well as for the interaction between the self-referential and the "cognitive" brain network in patients with MDD, leading potentially to impaired inhibitory control, ie, an important component of cognitive control.

\section{The search for clinical markers of SB}

The assessment of individual suicide risk is difficult for several reasons: 1) Patients may be unwilling or unable to report their intentions. 2) Suicidal acts may occur abruptly. 3) Discrimination of SI and suicidal intent is difficult. 4) There is a low base rate even in high-risk groups. ${ }^{9}$ Therefore, it has been argued that a personal history of suicide attempt remains the strongest predictive factor of future suicide. ${ }^{91,92}$ 
Given the comparably weak power of basic clinical assessment, there is a need for additional criteria and tests predicting SB more reliably. In the prior sections, we have underlined the significant role of hopelessness and impulsivity as components of the diathesis for SB. Hopelessness may be assessed with little effort by the Beck hopelessness scale. McMillan et al ${ }^{82}$ investigated the ability of the rating scale to predict suicide and nonfatal self-harm by performing a meta-analysis of follow-up studies. The authors reported that the scale measures identified high-risk groups but clinical use in detecting acute suicidality would be unlikely due to low specificity. Other items associated with SB are as follows: high psychological pain, ${ }^{93}$ negative life events, ${ }^{94}$ childhood adversities,${ }^{95}$ low CSF 5-hydroxyindoleacetic acid and Hypothalamic-pituitary-adrenal axis (HPA) axis dysfunction, ${ }^{9}$ serotonin polymorphism (5-HTTLPR), ${ }^{26}$ and SI. ${ }^{96}$ Unfortunately, none of the latter items is specific enough to allow for reliable prognosis in an individual clinical case. Most risk factors for SB have high sensitivity but comparably poor specificity.

In the search for markers of SB, neurocognitive and neurofunctional approaches appear most promising. According to the well-established impact of impulsivity in SB, neuropsychological studies often reported worse performance on cognitive tasks requiring response inhibition. ${ }^{97}$ Moreover, Keilp et $\mathrm{al}^{98}$ found impaired inhibition processes during Stroop task in depressed patients with SB compared to depressed patients without SB. Becker et $\mathrm{al}^{99}$ as well as Williams and Broadbent ${ }^{100}$ observed in suicide attempters impaired response inhibition in an emotional Stroop task with suicide-related words. Cha et a ${ }^{101}$ reported that suicidespecific attentional bias in the emotional Stroop task predicted above and beyond other clinical predictors who completed a suicide attempt within the next 6 months. Nock et al ${ }^{10}$ reported that implicit cognition of death and suicide as measured by a computer-administered neurocognitive paradigm exceeded the predictive validity of all known risk factors (eg, depression, suicide-attempt history) and both patients' and clinicians' predictions. We suggest that measures of implicit cognition - if results are replicated in larger future studies may be useful as a behavioral marker of SB.

Even more precise estimates may become possible by the use of functional and structural neuroimaging approaches and the rising number of specific circumscribed findings as depicted in previous sections. For example, with regard to potential neurofunctional markers, Willeumier et $\mathrm{al}^{12}$ investigated patients with mood disorders scanned previously by single photon emission computed tomography (SPECT) who completed suicide. The authors reported decreased regional cerebral blood flow (rCBF) in the subgenual ACC in 18 of the 21 subjects. Additionally, blood perfusion was decreased in the DLPFC. Regarding potential structural markers, Wagner et $\mathrm{al}^{11}$ investigated prefrontal cortical thickness in depressed patients with a high risk for SB. The main finding was that patients with a high risk for suicide showed significantly thinner cortex in the left DLPFC and VLPFC as well as in the ACC in contrast to non-high-risk patients (Figure 2). Thus, these functional and structural deficits may represent a neurobiological marker of SB, which may be directly related to reported deficits in emotional, cognitive, and behavioral control. If these findings can be replicated in larger samples by future studies, they possibly may be used as clinical markers for SB in psychiatric patients. However, a clinical strategy for predicting acute suicidality should be based on both trait-like characteristics such as neurobiological or behavioral markers and state-dependent stressors induced by psychiatric illness and psychosocial crises.

\section{Discussion}

SB represents a major health problem worldwide. Although SB occurs in association with MDD or other psychiatric disorders, there is evidence from genetic studies that it might represent a psychiatric disorder on its own. In nosological discussions during preparation of the Diagnostic and Statistical Manual of Mental Disorders, it has been proposed to create a separate diagnostic category for SB that should be documented on a sixth axis. ${ }^{102}$ At the end of this process, an agreement was reached about including "suicidal behavior disorder" as a "condition for further study". ${ }^{103}$

This review aimed to give a concise overview of the most significant neurobiological findings in SB. We provided evidence for specific dysfunctions within the serotonergic system, for distinct morphological abnormalities in the gray and white matter composition as well as for neurofunctional alterations in the fronto-striatal network.

In summary, neurochemical studies have often demonstrated abnormal serotonergic transmission in SB. In contrast, no consistent changes regarding dopaminergic or noradrenergic transmission were detected. A number of studies have focused on neurochemical indices in several areas of the frontal cortex, which is largely innervated by serotonergic projections from the DRN and MRN. The reported observations might imply an abnormal serotonergic modulation of the medial and lateral frontal brain areas, eg, VMPFC and DLPFC. The VMPFC/OFC and DLPFC are of eminent importance due to the involvement in 

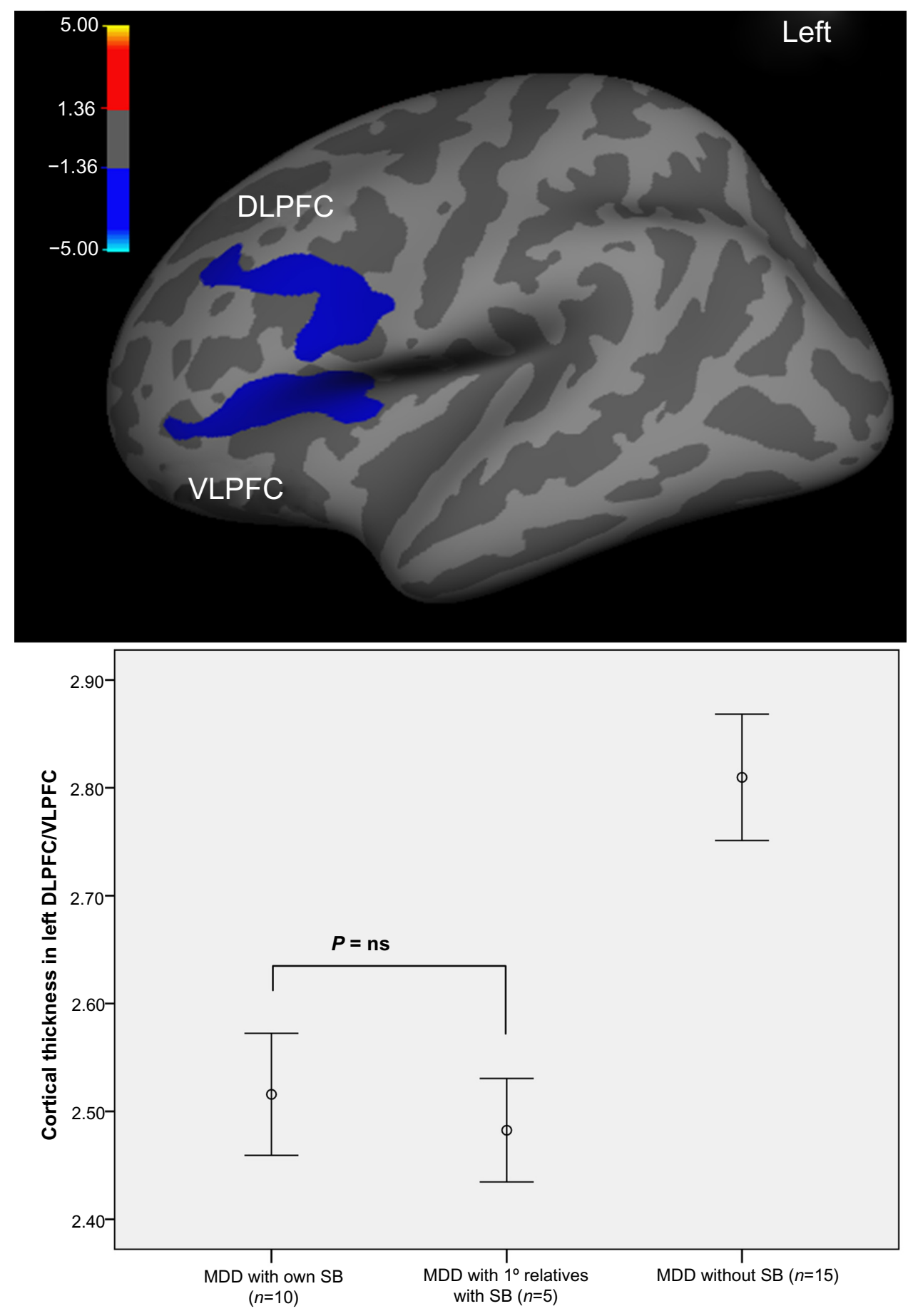

Figure 2 Brain regions of significant difference in cortical thickness between depressed patients with high risk for suicide compared with non-high-risk patient. Notes: Reprinted from: J Psychiatr Res., 20I2;46(II), Wagner G, Schultz CC, Koch K, Schachtzabel C, Sauer H, Schlosser RG. Prefrontal cortical thickness in depressed patients with high-risk for suicidal behavior. Pages I449-1455. Copyright 20I2, with permission from Elsevier."

Abbreviations: DLPFC, dorsolateral prefrontal cortex; VLPFC, ventrolateral prefrontal cortex; MDD, major depressive disorder; SB, suicidal behavior; ns, non-significant.

executive functions (inhibition of inappropriate responses/ behavior and decision making), in affective control, and in reward processing. Thus, altered serotonergic input to the VMPFC, OFC, and DLPFC may result in impaired affect regulation and behavioral control and lead, thereby, to a greater propensity to exhibit impulsive behavior or SB. Moreover, postmortem as well as in vivo studies that investigated brain structures in subjects with SB have repeatedly reported alterations in the neuronal/glial cell density and volumes in rather similar brain areas, ie, in 
the frontal, cingulate, and striatal brain regions as well as directly in the serotonin-producing raphe nuclei in the brainstem. With regard to white matter, abnormalities in the fronto-striatal connectivity have been found in SB by DTI studies. These results corroborate previous structural and postmortem findings of reduced frontal, cingulate, and striatal volume and provide strong evidence for a potential dysconnectivity in the fronto-striatal network in patients with SB.

According to the proposed diathesis-stress model, impulsivity and hopelessness are risk factors or trait-like components of the diathesis for SB. Both conditions may be accompanied by deficits in cognitive and affective control similar to the findings in SB. In impulsivity and SB, these deficits presumably are based on blunted activation of the fronto-striatal network, which is strongly involved in behavioral/affective control and reward processing. With regard to hopelessness and self-referential processing, the VMPFC appears to be a critical brain region due to the interaction between the self-referential and the "cognitive" brain network.

In consideration of the different methods applied in previous studies as well as small sample sizes, we tentatively concluded that the neurochemical as well as structural and functional neuroimaging findings converge at a point which implicates altered serotonergic neurotransmission and abnormal frontal cortical structure and function to be of major significance in $\mathrm{SB}$.

Nevertheless, in our opinion at present many issues remain unresolved. Despite the relatively consistent evidence of an association between SB and alterations in the fronto-striatal network, the present literature reveals a lack of knowledge with regard to the functional interplay within this network and its relationship to psychopathology. Up to date, no study has investigated the neural correlates of the postulated "traits" in SB, ie, impulsivity and hopelessness with appropriate neurocognitive and neurofunctional paradigms. Furthermore, the functional interplay between DRN and the fronto-striatal network in patients with SB has not been studied yet. Additionally, a combined analysis of function and structure in patients with SB has not been performed yet - for answering the open question - whether and to what extent structural alterations are related to changes in functional activation and functional or effective connectivity. Hopefully, these complex questions will be addressed in the future by strategic multimodal investigations.

In conclusion, the clinical assessment of individual suicide risk remains difficult. Thus, there is a need to find specific markers, which predict SB more reliably than currently available. Some recent neurocognitive and functional/structural neuroimaging findings might be appropriate for use as clinical indicators of SB within the near future. However, a clinical strategy for detection and timely treatment of acute suicidality should be based on both traitlike characteristics such as behavioral and neurobiological markers and state-dependent stressors such as psychiatric illness or psychosocial crises. Closely related to the treatment of SB is the issue of its prevention. Considering the huge human tragedy and the high economical costs for societies caused by $\mathrm{SB},{ }^{104}$ some countries have developed national suicide-prevention plans. Mann et al ${ }^{105}$ examined various suicide-preventive interventions and concluded that there is evidence for the effectiveness of only two prevention strategies: improving education of physicians in depression recognition and treatment as well as restricting access to lethal methods.

\section{Disclosure}

The authors report no conflicts of interest in this work.

\section{References}

1. United Nations. World Population Prospects: The 2008 Revision. New York: United Nations Publications; 2009.

2. Krug EG, Mercy JA, Dahlberg LL, Zwi AB. The world report on violence and health. Lancet. 2002;360(9339):1083-1088.

3. Arsenault-Lapierre G, Kim C, Turecki G. Psychiatric diagnoses in 3275 suicides: a meta-analysis. BMC Psychiatry. 2004;4:37.

4. Mann JJ. Neurobiology of suicidal behaviour. Nat Rev Neurosci. 2003; 4(10):819-828.

5. Andrade L, Caraveo-Anduaga JJ, Berglund P, et al. The epidemiology of major depressive episodes: results from the International Consortium of Psychiatric Epidemiology (ICPE) Surveys. Int J Methods Psychiatr Res. 2003;12(1):3-21.

6. Bostwick JM, Pankratz VS. Affective disorders and suicide risk: a reexamination. Am J Psychiatry. 2000;157(12):1925-1932.

7. Angst J, Angst F, Gerber-Werder R, Gamma A. Suicide in 406 mooddisorder patients with and without long-term medication: a 40 to 44 years' follow-up. Arch Suicide Res. 2005;9(3):279-300.

8. Ernst C, Mechawar N, Turecki G. Suicide neurobiology. Prog Neurobiol. 2009;89(4):315-333.

9. Mann JJ, Currier D. A review of prospective studies of biologic predictors of suicidal behavior in mood disorders. Arch Suicide Res. 2007;11(1):3-16.

10. Nock MK, Park JM, Finn CT, Deliberto TL, Dour HJ, Banaji MR. Measuring the suicidal mind: implicit cognition predicts suicidal behavior. Psychol Sci. 2010;21(4):511-517.

11. Wagner G, Schultz CC, Koch K, Schachtzabel C, Sauer H, Schlosser RG. Prefrontal cortical thickness in depressed patients with high-risk for suicidal behavior. J Psychiatr Res. 2012;46(11):1449-1455.

12. Willeumier K, Taylor DV, Amen DG. Decreased cerebral blood flow in the limbic and prefrontal cortex using SPECT imaging in a cohort of completed suicides. Transl Psychiatry. 2011;1:e28.

13. Preti A. Animal model and neurobiology of suicide. Prog Neuropsychopharmacol Biol Psychiatry. 2011;35(4):818-830.

14. Voracek M, Loibl LM. Genetics of suicide: a systematic review of twin studies. Wien Klin Wochenschr. 2007;119(15-16):463-475. 
15. Brent DA, Melhem N. Familial transmission of suicidal behavior. Psychiatr Clin North Am. 2008;31(2):157-177.

16. Mann JJ, Arango VA, Avenevoli S, et al. Candidate endophenotypes for genetic studies of suicidal behavior. Biol Psychiatry. 2009;65(7): 556-563.

17. Malafosse A. Genetics of suicidal behavior. Am J Med Genet C Semin Med Genet. 2005;133C(1):1-2.

18. Leboyer M, Slama F, Siever L, Bellivier F. Suicidal disorders: a nosological entity per se? Am J Med Genet C Semin Med Genet 2005;133C(1):3-7.

19. Turecki G. Dissecting the suicide phenotype: the role of impulsiveaggressive behaviours. J Psychiatry Neurosci. 2005;30(6): 398-408.

20. Dumais A, Lesage AD, Alda M, et al. Risk factors for suicide completion in major depression: a case-control study of impulsive and aggressive behaviors in men. Am J Psychiatry. 2005;162(11): 2116-2124.

21. McGirr A, Alda M, Seguin M, Cabot S, Lesage A, Turecki G. Familial aggregation of suicide explained by cluster B traits: a three-group family study of suicide controlling for major depressive disorder. Am J Psychiatry. 2009;166(10):1124-1134.

22. Kim CD, Seguin M, Therrien N, et al. Familial aggregation of suicidal behavior: a family study of male suicide completers from the general population. Am J Psychiatry. 2005;162(5):1017-1019.

23. Lidberg L, Belfrage H, Bertilsson L, Evenden MM, Asberg M. Suicide attempts and impulse control disorder are related to low cerebrospinal fluid 5-HIAA in mentally disordered violent offenders. Acta Psychiatr Scand. 2000;101(5):395-402.

24. Roy A, Rylander G, Forslund K, et al. Excess tryptophan hydroxylase 17 $779 \mathrm{C}$ allele in surviving cotwins of monozygotic twin suicide victims. Neuropsychobiology. 2001;43(4):233-236.

25. Bah J, Lindström M, Westberg L, et al. Serotonin transporter gene polymorphisms: effect on serotonin transporter availability in the brain of suicide attempters. Psychiatry Res. 2008;162(3):221-229.

26. Neves FS, Malloy-Diniz LF, Romano-Silva MA, Aguiar GC, de Matos LO, Correa H. Is the serotonin transporter polymorphism (5-HTTLPR) a potential marker for suicidal behavior in bipolar disorder patients? J Affect Disord. 2010;125(1-3):98-102.

27. Antypa N, Serretti A, Rujescu D. Serotonergic genes and suicide: a systematic review. Eur Neuropsychopharmacol. 2013;23(10) $1125-1142$.

28. Mann JJ. The neurobiology of suicide. Nat Med. 1998;4(1):25-30.

29. Joiner TE Jr, Brown JS, Wingate LR. The psychology and neurobiology of suicidal behavior. Annu Rev Psychol. 2005;56:287-314.

30. Stockmeier CA, Shapiro LA, Dilley GE, Kolli TN, Friedman L, Rajkowska G. Increase in serotonin-1A autoreceptors in the midbrain of suicide victims with major depression-postmortem evidence for decreased serotonin activity. J Neurosci. 1998;18(18) 7394-7401.

31. Bach-Mizrachi H, Underwood MD, Kassir SA, et al. Neuronal tryptophan hydroxylase mRNA expression in the human dorsal and median raphe nuclei: major depression and suicide. Neuropsychopharmacology. 2006;31(4):814-824

32. Bach-Mizrachi H, Underwood MD, Tin A, Ellis SP, Mann JJ, Arango V. Elevated expression of tryptophan hydroxylase-2 mRNA at the neuronal level in the dorsal and median raphe nuclei of depressed suicides. Mol Psychiatry. 2008;13(5):507-513,465.

33. Cannon DM, Ichise M, Fromm SJ, et al. Serotonin transporter binding in bipolar disorder assessed using [11C]DASB and positron emission tomography. Biol Psychiatry. 2006;60(3):207-217.

34. Miller JM, Hesselgrave N, Ogden RT, et al. Positron emission tomography quantification of serotonin transporter in suicide attempters with major depressive disorder. Biol Psychiatry. 2013;74(4) 287-295.

35. Nye JA, Purselle D, Plisson C, et al. Decreased brainstem and putamen SERT binding potential in depressed suicide attempters using [11C]-zient PET imaging. Depress Anxiety. 2013;30(10):902-907.
36. Ryding E, Ahnlide JA, Lindstrom M, Rosen I, Traskman-Bendz L. Regional brain serotonin and dopamine transporter binding capacity in suicide attempters relate to impulsiveness and mental energy. Psychiatry Res. 2006;148(2-3):195-203.

37. Currier D, Mann JJ. Stress, genes and the biology of suicidal behavior. Psychiatr Clin North Am. 2008;31(2):247-269.

38. Mann JJ, Huang YY, Underwood MD, et al. A serotonin transporter gene promoter polymorphism (5-HTTLPR) and prefrontal cortical binding in major depression and suicide. Arch Gen Psychiatry. 2000;57(8): 729-738.

39. Arango V, Underwood MD, Gubbi AV, Mann JJ. Localized alterations in pre- and postsynaptic serotonin binding sites in the ventrolateral prefrontal cortex of suicide victims. Brain Res. 1995;688(1-2): 121-133.

40. Audenaert K, Van Laere K, Dumont F, et al. Decreased frontal serotonin 5-HT 2a receptor binding index in deliberate self-harm patients. Eur J Nucl Med. 2001;28(2):175-182.

41. Leyton M, Paquette V, Gravel P, et al. alpha-[11C]MethylL-tryptophan trapping in the orbital and ventral medial prefrontal cortex of suicide attempters. Eur Neuropsychopharmacol. 2006;16(3): $220-223$.

42. Oquendo MA, Placidi GP, Malone KM, et al. Positron emission tomography of regional brain metabolic responses to a serotonergic challenge and lethality of suicide attempts in major depression. Arch Gen Psychiatry. 2003;60(1):14-22.

43. Nieuwenhuys R. Chemoarchitecture of the Brain. Berlin: Springer; 1985.

44. Higley JD, Thompson WW, Champoux M, et al. Paternal and maternal genetic and environmental contributions to cerebrospinal fluid monoamine metabolites in rhesus monkeys (Macaca mulatta). Arch Gen Psychiatry. 1993;50(8):615-623.

45. Rajkowska G, Miguel-Hidalgo JJ, Wei J, et al. Morphometric evidence for neuronal and glial prefrontal cell pathology in major depression. Biol Psychiatry. 1999;45(9):1085-1098.

46. Ongur D, Drevets WC, Price JL. Glial reduction in the subgenual prefrontal cortex in mood disorders. Proc Natl Acad Sci U S A. 1998; 95(22):13290-13295.

47. Mechawar N. Ce que la microscopie peut nous apprendre sur le suicide. [What can microscopy teach us on suicide?]. Sante Ment Que. 2012;37(2):57-64. French.

48. Hercher C, Canetti L, Turecki G, Mechawar N. Anterior cingulate pyramidal neurons display altered dendritic branching in depressed suicides. J Psychiatr Res. 2010;44(5):286-293.

49. Underwood MD, Khaibulina AA, Ellis SP, et al. Morphometry of the dorsal raphe nucleus serotonergic neurons in suicide victims. Biol Psychiatry. 1999;46(4):473-483.

50. Ahearn EP, Jamison KR, Steffens DC, et al. MRI correlates of suicide attempt history in unipolar depression. Biol Psychiatry. 2001;50(4): 266-270.

51. Monkul ES, Hatch JP, Nicoletti MA, et al. Fronto-limbic brain structures in suicidal and non-suicidal female patients with major depressive disorder. Mol Psychiatry. 2007;12(4):360-366.

52. Aguilar EJ, García-Martí G, Martí-Bonmatí L, et al. Left orbitofrontal and superior temporal gyrus structural changes associated to suicidal behavior in patients with schizophrenia. Prog Neuropsychopharmacol Biol Psychiatry. 2008;32(7):1673-1676.

53. Giakoumatos CI, Tandon N, Shah J, et al. Are structural brain abnormalities associated with suicidal behavior in patients with psychotic disorders? J Psychiatr Res. 2013;47(10):1389-1395.

54. Vang FJ, Ryding E, Traskman-Bendz L, van Westen D, Lindstrom MB. Size of basal ganglia in suicide attempters, and its association with temperament and serotonin transporter density. Psychiatry Res. 2010; 183(2):177-179.

55. Wagner G, Koch K, Schachtzabel C, Schultz CC, Sauer H, Schlosser RG. Structural brain alterations in patients with major depressive disorder and high risk for suicide: evidence for a distinct neurobiological entity? Neuroimage. 2011;54(2):1607-1614. 
56. Dombrovski AY, Siegle GJ, Szanto K, Clark L, Reynolds CF, Aizenstein $\mathrm{H}$. The temptation of suicide: striatal gray matter, discounting of delayed rewards, and suicide attempts in late-life depression. Psychol Med. 2012;42(6):1203-1215.

57. Ehrlich S, Breeze JL, Hesdorffer DC, et al. White matter hyperintensities and their association with suicidality in depressed young adults. J Affect Disord. 2005;86(2-3):281-287.

58. Ehrlich S, Noam GG, Lyoo IK, Kwon BJ, Clark MA, Renshaw PF. Subanalysis of the location of white matter hyperintensities and their association with suicidality in children and youth. Ann NY Acad Sci. 2003;1008:265-268.

59. Ehrlich S, Noam GG, Lyoo IK, Kwon BJ, Clark MA, Renshaw PF. White matter hyperintensities and their associations with suicidality in psychiatrically hospitalized children and adolescents. J Am Acad Child Adolesc Psychiatry. 2004;43(6):770-776.

60. Pompili M, Ehrlich S, De Pisa E, et al. White matter hyperintensities and their associations with suicidality in patients with major affective disorders. Eur Arch Psychiatry Clin Neurosci. 2007;257(8):494-499.

61. Pompili M, Innamorati M, Mann JJ, et al. Periventricular white matter hyperintensities as predictors of suicide attempts in bipolar disorders and unipolar depression. Prog Neuropsychopharmacol Biol Psychiatry. 2008;32(6):1501-1507.

62. Jia Z, Huang X, Wu Q, et al. High-field magnetic resonance imaging of suicidality in patients with major depressive disorder. Am J Psychiatry. 2010;167(11):1381-1390.

63. Jia Z, Wang Y, Huang X, et al. Impaired frontothalamic circuitry in suicidal patients with depression revealed by diffusion tensor imaging at 3.0 T. J Psychiatry Neurosci. 2013;39(3):170-177.

64. Mahon K, Burdick KE, Wu J, Ardekani BA, Szeszko PR. Relationship between suicidality and impulsivity in bipolar I disorder: a diffusion tensor imaging study. Bipolar Disord. 2012;14(1):80-89.

65. Olvet DM, Peruzzo D, Thapa-Chhetry B, et al. A diffusion tensor imaging study of suicide attempters. J Psychiatr Res. 2014;51:60-67.

66. Schmahmann J, Pandya D. Fiber Pathways of the Brain. New York: Oxford University Press; 2006.

67. Clark L, Robbins TW, Ersche KD, Sahakian BJ. Reflection impulsivity in current and former substance users. Biol Psychiatry. 2006;60(5): 515-522.

68. Patton JH, Stanford MS, Barratt ES. Factor structure of the Barratt impulsiveness scale. J Clin Psychol. 1995;51(6):768-774.

69. Boonstra AM, Oosterlaan J, Sergeant JA, Buitelaar JK. Executive functioning in adult ADHD: a meta-analytic review. Psychol Med. 2005;35(8):1097-1108.

70. Barratt ES, Stanford MS, Kent TA, Felthous A. Neuropsychological and cognitive psychophysiological substrates of impulsive aggression. Biol Psychiatry. 1997;41(10):1045-1061.

71. Chamberlain SR, Fineberg NA, Blackwell AD, Robbins TW, Sahakian BJ. Motor inhibition and cognitive flexibility in obsessive-compulsive disorder and trichotillomania. Am J Psychiatry. 2006;163(7): $1282-1284$

72. Chamberlain SR, Sahakian BJ. The neuropsychiatry of impulsivity. Curr Opin Psychiatry. 2007;20(3):255-261.

73. Bjork JM, Dougherty DM, Moeller FG, Swann AC. Differential behavioral effects of plasma tryptophan depletion and loading in aggressive and nonaggressive men. Neuropsychopharmacology. 2000;22(4): $357-369$.

74. Marsh DM, Dougherty DM, Moeller FG, Swann AC, Spiga R. Laboratory-measured aggressive behavior of women: acute tryptophan depletion and augmentation. Neuropsychopharmacology. 2002;26(5): 660-671.

75. Verbruggen F, Logan GD. Response inhibition in the stop-signal paradigm. Trends Cogn Sci. 2008;12(11):418-424.

76. Mansouri FA, Tanaka K, Buckley MJ. Conflict-induced behavioural adjustment: a clue to the executive functions of the prefrontal cortex. Nat Rev Neurosci. 2009;10(2):141-152.

77. Dombrovski AY, Szanto K, Clark L, Reynolds CF, Siegle GJ. Reward signals, attempted suicide, and impulsivity in late-life depression. JAMA Psychiatry. 2013;70(10):1020-1030.
78. Pan LA, Batezati-Alves SC, Almeida JR, et al. Dissociable patterns of neural activity during response inhibition in depressed adolescents with and without suicidal behavior. $J$ Am Acad Child Adolesc Psychiatry. 2011;50(6):602-611e603.

79. Frankle WG, Lombardo I, New AS, et al. Brain serotonin transporter distribution in subjects with impulsive aggressivity: a positron emission study with [11C]McN 5652. Am J Psychiatry. 2005;162(5): 915-923.

80. Soloff PH, Meltzer CC, Becker C, Greer PJ, Kelly TM, Constantine D. Impulsivity and prefrontal hypometabolism in borderline personality disorder. Psychiatry Res. 2003;123(3):153-163.

81. Beck AT, Weissman A, Lester D, Trexler L. The measurement of pessimism: the hopelessness scale. J Consult Clin Psychol. 1974;42(6): 861-865.

82. McMillan D, Gilbody S, Beresford E, Neilly L. Can we predict suicide and non-fatal self-harm with the Beck Hopelessness Scale? A meta-analysis. Psychol Med. 2007;37(6):769-778.

83. Young MA, Fogg LF, Scheftner W, Fawcett J, Akiskal H, Maser J. Stable trait components of hopelessness: baseline and sensitivity to depression. J Abnorm Psychol. 1996;105(2):155-165.

84. van Heeringen C, Audenaert K, Van Laere K, et al. Prefrontal 5-HT2a receptor binding index, hopelessness and personality characteristics in attempted suicide. J Affect Disord. 2003;74(2):149-158.

85. Northoff G, Heinzel A, de Greck M, Bermpohl F, Dobrowolny H, Panksepp J. Self-referential processing in our brain - a meta-analysis of imaging studies on the self. Neuroimage. 2006;31(1):440-457.

86. van der Meer L, Costafreda S, Aleman A, David AS. Self-reflection and the brain: a theoretical review and meta-analysis of neuroimaging studies with implications for schizophrenia. Neurosci Biobehav Rev. 2010;34(6):935-946.

87. Wagner G, Koch K, Schachtzabel C, et al. Self-referential processing influences functional activation during cognitive control: an fMRI study. Soc Cogn Affect Neurosci. 2012;8(7):828-837.

88. Lemogne C, Delaveau P, Freton M, Guionnet S, Fossati P. Medial prefrontal cortex and the self in major depression. J Affect Disord. 2012; 136(1-2):e1-e11.

89. Grimm S, Ernst J, Boesiger P, Schuepbach D, Boeker H, Northoff G. Reduced negative BOLD responses in the default-mode network and increased self-focus in depression. World J Biol Psychiatry. 2011;12(8): 627-637.

90. Cooney RE, Joormann J, Eugene F, Dennis EL, Gotlib IH. Neural correlates of rumination in depression. CognAffect Behav Neurosci. 2010; 10(4):470-478.

91. Hawton K, van Heeringen K. Suicide. Lancet. 2009;373(9672): 1372-1381.

92. Suominen K, Isometsa E, Suokas J, Haukka J, Achte K, Lonnqvist J. Completed suicide after a suicide attempt: a 37-year follow-up study. Am J Psychiatry. 2004;161(3):562-563.

93. Olie E, Guillaume S, Jaussent I, Courtet P, Jollant F. Higher psychological pain during a major depressive episode may be a factor of vulnerability to suicidal ideation and act. J Affect Disord. 2010;120(1-3): 226-230.

94. Heikkinen ME, Aro HM, Henriksson MM, et al. Differences in recent life events between alcoholic and depressive nonalcoholic suicides. Alcohol Clin Exp Res. 1994;18(5):1143-1149.

95. Johnson JG, Cohen P, Gould MS, Kasen S, Brown J, Brook JS. Childhood adversities, interpersonal difficulties, and risk for suicide attempts during late adolescence and early adulthood. Arch Gen Psychiatry. 2002;59(8):741-749.

96. Williams JM, Crane C, Barnhofer T, Van der Does AJ, Segal ZV. Recurrence of suicidal ideation across depressive episodes. $J$ Affect Disord. 2006;91(2-3):189-194.

97. Jollant F, Lawrence NL, Olie E, Guillaume S, Courtet P. The suicidal mind and brain: a review of neuropsychological and neuroimaging studies. World J Biol Psychiatry. 2011;12(5):319-339.

98. Keilp JG, Gorlyn M, Oquendo MA, Burke AK, Mann JJ. Attention deficit in depressed suicide attempters. Psychiatry Res. 2008;159(1-2): $7-17$. 
99. Becker ES, Strohbach D, Rinck M. A specific attentional bias in suicide attempters. J Nerv Ment Dis. 1999;187(12):730-735.

100. Williams JM, Broadbent K. Distraction by emotional stimuli: use of a Stroop task with suicide attempters. Br J Clin Psychol. 1986;25(pt 2): 101-110.

101. Cha CB, Najmi S, Park JM, Finn CT, Nock MK. Attentional bias toward suicide-related stimuli predicts suicidal behavior. $J$ Abnorm Psychol. 2010;119(3):616-622.

102. Oquendo MA, Baca-Garcia E, Mann JJ, Giner J. Issues for DSM-V: suicidal behavior as a separate diagnosis on a separate axis. Am J Psychiatry. 2008;165(11):1383-1384.
103. American Psychiatric Association. Diagnostic and Statistical Manual of Mental Disorders. 5th ed. Arlington: American Psychiatric Publishing; 2013.

104. Murray CJL, Lopez AD. The Global Burden of Disease: A Comprehensive Assessment of Mortality and Disability from Diseases, Injuries and Risk Factors in 1990 and Projected to 2020. Cambridge, MA: Harvard School of Public Health; 1996.

105. Mann JJ, Apter A, Bertolote J, et al. Suicide prevention strategies: a systematic review. JAMA. 2005;294(16):2064-2074.

Reports in Medical Imaging

\section{Publish your work in this journal}

Reports in Medical Imaging is an international, peer-reviewed, open access journal publishing original research, reports, reviews and commentaries on all areas of medical imaging. The manuscript management system is completely online and includes a very quick and fair peer-review system, which is all easy to use.

\section{Dovepress}

Visit http://www.dovepress.com/testimonials.php to read real quotes from published authors. 